\title{
PAPER
}

\section{Multiple sclerosis in Malta in 1999: an update}

\section{G Dean, M Elian, A Galea de Bono, R Pace Asciak, N Vella, V Mifsud, J Aquilina}

See end of article for authors' affiliations

....................

Correspondence to: Dr G Dean, Box 1851, Ballsbridge, Dublin, Ireland; hrb@hrb.ie

Received 3 August 2001 In revised form 2 April 2002 Accepted 3 April 2002

\begin{abstract}
Objectives: To ascertain the prevalence of multiple sclerosis (MS) in the islands of Malta and compare it with a previous study undertaken 21 years earlier, when a remarkably low prevalence was found. Method: Deaths with MS on the death certificate since the last study were reviewed. Sources of information about new patients were the Hospital Activity Analysis scheme, the MS Society of Malta, the records of the state hospitals, long stay private hospitals and nursing homes, lists provided by the state pharmacies, and magnetic resonance imaging, cerebrospinal fluid, and evoked response studies. Prevalence day was 1 January 1999. The Poser classification was used.

Results: Since 1978, 17 patients had died with a verified diagnosis of MS on the death certificate. They included all 10 deaths with MS from the original study and two immigrants. Fifty patients had clinically definite MS (CDMS) and 13 clinically probable MS (CPMS). The prevalence of CDMS was 13.2/100 000 (male 11.2, female 15.2). The prevalence of CDMS and CPMS combined was 16.7/ 100000 (male 13.3, female 19.9). The annual incidence was $0.7 / 100000$. Twelve patients were found with CDMS among the 7213 immigrants resident in Malta (166/100 000). The expected rate was $1 / 100000$, determined at Maltese born rates. There were major changes in the population distribution during the 21 years between the two studies, with a big increase in the age groups with a high risk of MS. There is a longer expectation of life and the diagnosis in now made earlier.

Conclusion: Malta still has a low MS prevalence. In comparison with Sicily and other Mediterranean countries of Europe it offers an opportunity to ascertain the genetic and environmental factors responsible for the disease.
\end{abstract}

p n a study in Greater London and the West Midlands a high prevalence of multiple sclerosis (MS) was found among those discharged from hospital between 1960 and 1972 who were immigrants from Europe, with the exception of immigrants from Malta. In this study the calculated expected number of patients with MS born in Malta, at the England and Wales rate, was 10. However, no Maltese born patients were found. In contrast the number of patients with MS born in nearby Italy was little different from the expected number. $^{12}$

The absence of hospitalised patients with MS among immigrants from Malta to England prompted a study in the islands of Malta and Gozo in 1975-8. ${ }^{3}$ Malta has had a medical school since 1676. English is commonly spoken and medical records are kept in English. Patients who were suspected of having MS were frequently sent to England for further investigation. Despite an intensive search in the Maltese islands on prevalence day, 1 January 1978, only 14 were found with a diagnosis of MS, one of whom had neuromyelitis optica (Devic's syndrome). Eleven were living in Malta and three in the nearby island of Gozo. A further patient with MS was overseas at the time of the study. Three had a diagnosis of possible MS.

Nine of the 14 patients with MS in the previous study had been investigated at London teaching hospitals. None of the patients with MS were related. During the 10 years (1967-76) MS was recorded as a cause of death on only six death certificates in Malta, ${ }^{4}$ and in five of these the history and clinical findings confirmed the diagnosis. The sixth was incorrectly certified.

Concurrently with the 1975-8 study on MS prevalence in Malta a similar study was undertaken in the city of Enna in central Sicily, where 15 patients with MS were found in a population of 29189 , or 53/100 000. The high prevalence in Enna in comparison with Malta was subsequently confirmed in three other cities of Sicily-Agrigento, ${ }^{6}$ Monreale, ${ }^{7}$ and Caltanisetta ${ }^{8}$-as well as in the Republic of San Marino. ${ }^{9}$
The present study aimed at ascertaining the changes in the prevalence of MS in Malta since the previous study and to ascertain whether the low MS prevalence found in Malta in 1978 was persisting.

\section{METHOD}

In Malta medical records are well kept. A national identification numbering system was started in 1978 and is now fully installed. The last two numbers on the identification code are the date of registration, which is generally the year of birth. Patients receive free medical care at the state hospitals: St Luke's Hospital in Malta and the General Hospital in Gozo. They collaborated with the study, as did the long stay Sir Paul Boffa Hospital and St Vincent De Paule Residence, 12 private nursing homes, and 20 homes with a total of 703 residents under the aegis of the church.

Patients suspected of having MS were frequently referred abroad for a magnetic resonance imaging (MRI) investigation. Since 1997 MRI studies have been undertaken in Malta. Cerebrospinal fluid was sent abroad for some patients for IgG studies.

Information was obtained from the central register of the Hospital Activity Analysis scheme and the records of the hospitals, nursing homes, and consultants. A list was prepared of all patients who had received drugs for the treatment of MS from the state hospitals, which are provided without cost.

Two of us (GD and ME) attended the 1999 annual meeting of the Multiple Sclerosis Society of Malta. The society had been founded in 1997, and the three consultant neurologists are now medical advisers to the Society (NV, GdeB, and VM). The secretary and members of the society collaborated with

Abbreviations: CDMS, clinically definite multiple sclerosis; CPMS clinically probable multiple sclerosis; MRI, magnetic resonance imaging; MS, multiple sclerosis 
Table 1 Maltese population in 1998 and 1976 and the calculated expected number of patients with multiple sclerosis (MS) in 1976 at the 1998 rates

\begin{tabular}{|c|c|c|c|c|c|c|}
\hline Age group (years) & $\begin{array}{l}\text { Population } 1998 \\
(\times 1000)\end{array}$ & $\begin{array}{l}\text { CDMS } 1 \text { January } \\
1999\end{array}$ & $\begin{array}{l}\text { Population } 1976 \\
(\times 1000)\end{array}$ & $\begin{array}{l}\text { Expected CDMS } \\
1976 \text { population }\end{array}$ & $\begin{array}{l}\text { CDMS + CPMS } \\
1 \text { January } 1999\end{array}$ & $\begin{array}{l}\text { Expected CDMS + CPMS } \\
1976 \text { population }\end{array}$ \\
\hline \multicolumn{7}{|l|}{ Males } \\
\hline $0-24$ & 70.4 & & 69.2 & & & \\
\hline $25-29$ & 12.5 & 1 & 13.7 & 1.1 & 1 & 1.1 \\
\hline $30-34$ & 11.9 & 2 & 8.8 & 1.5 & 2 & 1.5 \\
\hline $35-39$ & 14.2 & 8 & 8.0 & 4.5 & 9 & 5.1 \\
\hline $40-44$ & 14.7 & 3 & 7.4 & 1.5 & 3 & 1.5 \\
\hline $45-49$ & 14.2 & 0 & 7.3 & 0 & 2 & 1.0 \\
\hline $50-54$ & 14.7 & 5 & 7.6 & 2.6 & 5 & 2.6 \\
\hline $55-59$ & 8.1 & 1 & 5.9 & 0.7 & 1 & 0.7 \\
\hline $60-64$ & 8.2 & 1 & 5.2 & 0.6 & 2 & 1.3 \\
\hline$\geqslant 65$ & 18.9 & 0 & 11.6 & 0 & 0 & 0 \\
\hline Total males & 187.7 & 21 & 144.6 & 12.5 & 25 & 14.8 \\
\hline \multicolumn{7}{|l|}{ Females } \\
\hline $0-24$ & 65.9 & 0 & 66.1 & & & \\
\hline $25-29$ & 11.8 & 4 & 14.9 & 5.1 & 5 & 6.3 \\
\hline $30-34$ & 11.4 & 3 & 10.7 & 2.7 & 6 & 5.6 \\
\hline $35-39$ & 13.8 & 3 & 9.8 & 2.1 & 3 & 2.1 \\
\hline $40-44$ & 14.2 & 7 & 9.5 & 4.7 & 8 & 5.4 \\
\hline $45-49$ & 14.0 & 4 & 8.7 & 2.5 & 6 & 3.7 \\
\hline $50-54$ & 15.0 & 3 & 8.3 & 1.7 & 4 & 2.2 \\
\hline $55-59$ & 8.8 & 3 & 6.6 & 2.3 & 4 & 3.0 \\
\hline $60-64$ & 9.3 & 2 & 5.9 & 1.3 & 2 & 1.3 \\
\hline$\geqslant 65$ & 26.4 & 0 & 15.3 & 0 & 0 & 0 \\
\hline Total females & 190.8 & 29 & 155.8 & 22.4 & 38 & 29.6 \\
\hline Total & 378.5 & 50 & 300403 & 34.9 & 63 & 44.4 \\
\hline
\end{tabular}

the study. Many other physicians, ophthalmologists, and physiotherapists aided us by providing information about possible patients with MS. The national mortality register kept by the Department of Health Information service provided details of those who had MS mentioned on the death certificate. The case notes of every patient were studied and discussed.

The first of January 1999 was chosen as prevalence day. The calculated Maltese born population on this day was 378 518; 349338 were born in the island of Malta and 29180 in the island of Gozo (male 187689 , female 190829 ). This population is based on the 1995 census and the births and deaths since then. The foreign born population of the Maltese Islands at the 1995 census was 7213 (male 3101, female 4112). The Central Office of Statistics considers that there were about the same number of "foreign born" residents in the islands on prevalence day. Patients were classified according to the criteria of Poser et al. ${ }^{10}$

\section{RESULTS}

Deaths certified as MS or disseminated sclerosis on the death certificate

Twenty four patients were certified as having MS or disseminated sclerosis on the death certificate during the 21 years from l January 1978 to I January 1999. We studied their medical records and consulted with their doctors and families. For seven, either the diagnosis or the code on the death certificate was incorrect: amyotrophic lateral sclerosis was the correct diagnosis in three; another three had Guillain-Barré syndrome, hereditary ataxia, and autoimmune disease; and the seventh was depressed, and he was bedridden but not paralysed.

Ten of the 14 patients who had a diagnosis of MS in the 1975-8 study had died. MS or disseminated sclerosis was mentioned on the death certificate of all 10. Eight of the 10 had died by 1990. Three patients who had died and were certified as having MS diagnosable by prevalence day 1999 had not been included in the earlier study. One had been traced just after the study was closed and was included in a subsequent study on HLA patterns in Malta and Sicily, ${ }^{11}$ and two were not seen until after the study was closed. Two patients had their first MS symptoms after prevalence day 1978 and died before prevalence day 1999. Two of the 17 who died were immigrants: one from England and one from Australia. The mean age at death of the 10 who had died and were included in the 1978 study was 47.3 years and of all 15 MS deaths among the Maltese born it was 51.1 years. Using the Poser classification, introduced in 1983, 16 of the 17 Maltese born patients in the 1978 study would in retrospect have been found to have clinically definite MS (CDMS). One on follow up did not have MS but bilateral carotid occlusion. If the three patients with MS omitted from the earlier study are included the total number in January 1978 is increased from 13 to 16 or 5/100 000 population.

\section{Prevalence of MS in 1999}

On prevalence day 1999, 50 Maltese born patients were found who met the Poser diagnostic criteria for CDMS, ${ }^{10}$ including five with laboratory supported clinically definite MS (male 21, female 29). A further 13, four male and nine female patients, had clinically probable MS (CPMS). The prevalence of CDMS among the Maltese born was 13.2/100 000 (male 11.2 , female 15.2/100 000). The prevalence rate for the 63 CDMS and CPMS combined was 16.7/100 000 (male 13.3, female 19.9/100 000). Forty two of the 50 patients with CDMS had had an MRI study, 32 in England. Eight patients had not had an MRI investigation; they had a long history and the typical exacerbations and remissions that occur with the disease.

Three of the 13 patients with CPMS had had an MRI examination. Cerebrospinal fluid was sent to England or Germany from 14 patients suspected of having MS, and oligoclonal bands were reported in five of them. The mean age of the 50 patients with CDMS was 43.5 years (male 43.2, female 43.8 years). The mean age of the 63 patients with CDMS and CPMS combined was 43.4 years. Five of the 50 patients with CDMS were born in the island of Gozo, not different from 4.4, the expected number at the island of Malta rate. In three families two siblings had MS and one patient with MS had a cousin with MS. There was no evidence of any clinical difference in 
Table 2 Increased life expectancy during 1977-98 in the Maltese population

\begin{tabular}{|c|c|c|c|c|c|c|c|}
\hline \multirow[b]{2}{*}{ Age (years) } & \multicolumn{2}{|l|}{1977} & \multicolumn{2}{|l|}{1998} & \multicolumn{3}{|c|}{ Increased life expectancy (years) } \\
\hline & M & $\mathrm{F}$ & $M$ & $\mathrm{~F}$ & $M$ & $\mathrm{~F}$ & Mean \\
\hline 20 & 49.2 & 54.7 & 55.5 & 60.6 & 6.3 & 5.9 & 6.1 \\
\hline 30 & 39.5 & 44.9 & 45.8 & 50.7 & 6.3 & 6.0 & 6.1 \\
\hline 40 & 29.7 & 35.2 & 36.4 & 40.9 & 6.7 & 5.7 & 6.2 \\
\hline 50 & 20.6 & 25.7 & 27.7 & 31.3 & 7.1 & 5.6 & 6.4 \\
\hline
\end{tabular}

the presentation and development of MS between the Maltese and other populations studied in Europe and North America.

The annual incidence based on the reported first symptom of MS and including seven patients who had MS diagnosed after prevalence day was $0.7 / 100000$ during the 20 years 1979-98. There was little difference in the annual incidence between the 10 year periods $1979-88$ (0.6/100 000) and 1989-98 (0.8/100 000).

Twelve patients had a diagnosis of optic neuritis confirmed by the visually evoked response but with no other symptoms to suggest MS. A further 10 patients were excluded because they did not satisfy the Poser classification.

\section{MS among foreign born residents in Malta}

There were 12 foreign born residents with CDMS on prevalence day, six male and six female patients. Four of the 12 had a diagnosis of MS before they came to Malta but did not come to Malta because of the disease. Their mean age on prevalence day was 45.3 years. Twelve patients with MS among immigrants resident in Malta in a population of 7213 (1995 census), or $166 / 100000$, is a high prevalence, similar to that found in northern Europe. The calculated expected number of immigrants with CDMS at the Maltese born rate is 0.9/100 000 . Eight of the 12 foreign born residents did not have Maltese parents. Three of them had one Maltese parent and in only one foreign born patient were both parents Maltese born.

Two of the 17 reported MS deaths between 1978 and 1999 and two of nine post-prevalence day patients with MS were also foreign born residents in Malta. Three of these four had foreign born parents and one had Maltese parents. Fourteen of the 16 patients with MS who had been born abroad and were resident in Malta had either both or one non-Maltese parent.

\section{Changes in age distribution and in life expectancy of the Maltese population 1976-98}

There was a major change in the age distribution of the population of Malta between 1976 and 1998, the two years for which we have this information. ${ }^{412}{ }^{13}$ This was because there had been massive emigration of those aged 20-50 from Malta after the 1939-45 war, and this is the age group in which MS is most likely to occur (table 1 ). If the Maltese population in 1998 had had the same age distribution as in 1976, then the calculated expected number of patients with CDMS in 1998 would be reduced from 50 to 34.9 .

A further major change in the population in Malta has been the big increase in life expectancy. For those in the MS age group of 20 and 50 years, the mean increase in life expectancy was more than six years between 1977 and 1998 (table 2). ${ }^{12}{ }^{13}$ There has also been an increase in life expectancy among patients with MS. The mean age of the CDMS patients on prevalence day 1978 was 36.8 years, compared with a mean age of 43.5 years in January 1999, an increase of 6.7 years between the two studies. The increase in life expectancy among patients with MS was similar to that in the general population. The period between the reported onset of a first symptom of MS and diagnosis has also fallen from a mean of 4.3 to 2.6 years with increased awareness of the disease, the appointment of consultant neurologists to the department of neurology at the medical school-three by the year 2000 - and by the use of MRI studies. The calculated expected number of patients with CDMS in 1978, based on the number in 1999 and the changes in the population distribution between the two studies, is reduced from 50 to 35 . This would be further reduced by at least a third from 35 to 23 because of the longer life expectancy (table $3^{3}$ ) and earlier diagnosis of the patients in the 1999 study. Twenty three is not significantly different from 16, the corrected number of patients with CDMS found in the 1978 study $\left(\chi^{2}=3.1 . \mathrm{p}<0.05\right)$. There is no evidence of any significant change in the risk of developing MS in Malta between 1978 and 1999.

The expected number of patients with CDMS in Malta in 1999 , if the population is age standardised to the population of England and Wales (1991), would be 48.4. If it is age standardised to the European population ${ }^{14}$ it would be 54.4, not significantly different from the actual number (50).

\begin{tabular}{|c|c|c|c|}
\hline & Male & Female & Total \\
\hline \multicolumn{4}{|l|}{ Prevalence day, 1 January 1978} \\
\hline Number & 7 & 6 & 13 \\
\hline Diagnosed & 30.8 & 29.2 & 29.9 \\
\hline Mean age on 1 January 1978 & 37.7 & 35.4 & $36.8^{*}$ \\
\hline Mean age at death (10 of 13) by 1 January 1999 & 46.6 & 49.0 & $47.3 \dagger$ \\
\hline Mean age, all MS deaths 1978-99 & 50.2 & 51.8 & $51.1 \ddagger$ \\
\hline \multicolumn{4}{|l|}{ Prevalence day January 11999} \\
\hline CDMS number & 21 & 29 & 50 \\
\hline CPMS number & 4 & 9 & 13 \\
\hline Mean age when CDMS diagnosed & 32.1 & 30.0 & 31.1 \\
\hline Mean age on 1 January 1999 & 43.2 & 43.8 & $43.5^{*}$ \\
\hline Mean age, CDMS + CPMS 1998 on 1 January 1999 & 43.5 & 43.4 & 43.4 \\
\hline
\end{tabular}

*The mean age of patients with MS on prevalence day 1999 was 6.7 years older than in 1978 . †The three remaining patients from the 1978 study who were alive on prevalence day 1999 were aged 45 45 , and 61 .

flncluding three who in retrospect could have been included in the earlier report. 
That MS is uncommon among the Maltese born is confirmed by the small number of reported deaths from MS among Maltese immigrants to England, Wales, and Australia. Two deaths were reported among Maltese immigrants to England and Wales from 1968-87 (Office of Population Statistics and Surveys, London, personal communication, 1993). ${ }^{14}$ One of the two had been included in the earlier study on the prevalence of MS in Malta. ${ }^{3}$ at which time he was resident in Malta, and the second was an Englishman who had been born in Malta. The population of Maltese immigrants in England and Wales at the 1981 census was 34007 . Only three deaths from MS were reported among Maltese immigrants to Australia between 1968 and 1987 and the expected number at the England and Wales rate was 16.3. In contrast, 18 deaths were reported from amyotrophic lateral sclerosis and the expected number was 12.2. Between 1946 and 1975, 80333 Maltese had emigrated from Malta to Australia. The Maltese born population aged over 15 was 53136 in $1976 .{ }^{15}$

\section{DISCUSSION}

The prevalence of MS in the Maltese born population was higher in the present study than that reported in 1978. This increase is due to the changes that have occurred in the age distribution of the population between the two studies, the increased life expectancy of the population and of patients with MS, and earlier diagnosis. Studies of MS prevalence elsewhere have usually found an increase; for instance, the prevalence in Enna in Sicily increased from 53/100 000 in $1975^{5}$ to 120/100 000 in 1995. ${ }^{16}$ In Monreale there was an increase from $43 / 100000$ in $1980^{7}$ to $73 / 100000$ in $1991^{17}$ and in the island of Sardinia from $59 / 100000$ in $1980^{18}$ to $152 / 100000$ in $1994 .^{19}$ Some or all of the increase may be due to changes in the population distribution, longer life expectancy, and earlier diagnosis. Other Mediterranean countries of Europe besides the islands of Sicily and Sardinia have a relatively high MS prevalence: mainland Italy, ${ }^{20-22}$ Spain ${ }^{23-25}$ Greece, ${ }^{26}$ and Greek and Turkish speaking Cyprus. ${ }^{27}{ }^{28}$ The prevalence of MS has also increased in follow up studies in northern Europe, for example, in the Orkney Islands from 84/100 000 in 1954 to 258/100 000 in 1974, and in the Shetland Islands from $118 / 100000$ in 1954 to $152 / 100000$ in $1974 .^{29}$ The present study shows that, in contrast to the Maltese born, immigrants from Europe, Canada, and Australia to Malta also have a high MS prevalence.

The Maltese speak a Semitic language and generally have Semitic surnames, evidence of a prominent influence from North Africa, probably following the invasion by Habasa in AD 869-870. There is good reason therefore to expect that the genetic make up of the Maltese differs significantly from that in the rest of Europe. The prevalence of MS in Tunis is also reported to be low. ${ }^{30}$

A low frequency of a genetic predisposition to MS in the Maltese born appears to be the most likely cause of the low MS prevalence. In the 1970s a study was undertaken to compare the HLA factors between MS patients and controls in Malta and in Sicily. In Sicilian patients with MS, the frequency of DR2 was greater than in controls, and four of five DR2 positive patients also typed as Dw2. In the Maltese population DR2 was present at a high frequency but approximately half of the DR2 positive people did not type as Dw2, so that DR2 was probably most commonly present as part of class II haplotypes other than those commonly associated with MS. Additional differences in HLA profile between the Sicilian and Maltese populations were found when HLA A-A, -B, and B-DR antigen associations were examined. ${ }^{11}$ Therefore, some but by no means all of the difference in MS prevalence may be explained by these genetic factors. Further studies, using the advances in DNA technology made in the past 20 years, may add to understanding why there is a low prevalence of MS among the Maltese born.
Environmental factors may also be implicated. Immigrants from India and the West Indies to England and Wales have a low MS prevalence but their children born in England and Wales, in the age groups available for study, had a high prevalence similar to the prevalence in those born in the United Kingdom. ${ }^{31}{ }^{32}$ If the environmental factor is important the children born in the United Kingdom, Australia, and Canada to Maltese immigrants may have a much higher MS prevalence than that of their Maltese born parents. If this is occurring, it would throw light on the importance of environment in causing the disease.

The low prevalence of MS in the Maltese born, whether they are living in Malta or elsewhere, persists and offers a unique opportunity to ascertain the relative importance of the genetic and environmental factors responsible for MS.

\section{ACKNOWLEDGEMENTS}

We thank Mrs Louise Gusman, the secretary of the MS Society of Malta, and Mrs Rose Grech, who founded the Society. Professor Frederick Fenech advised us both in our earlier study and in the present one.

Dr Patrick Pullicino used a special questionnaire for MS patients when he was a member of the staff at St Luke's Hospital. The Health Information Service gave us their continued support as did Ms Margaret Baldacchino of the records department in St Luke's Hospital and Ms Mary Borg and Ms Antonella Xerri of the records department in Gozo Hospital. Mr Noel Beck carried out the visual evoked response tests and Mr Silvio Bugeja provided invaluable general assistance. Many other doctors and paramedical staff also helped us. Mr Tony Vincent of Demographics Ireland assisted us. We thank especially the patients with multiple sclerosis who so willingly collaborated with us.

The study was partly funded by a grant from the Multiple Sclerosis Society of the Republic of Ireland.

\section{Authors' affiliations}

G Dean, Health Research Board, Dublin, Ireland

M Elian, Central Middlesex Hospital, London, UK

A Galea de Bono, N Vella, V Mifsud, J Aquilina, St Luke's Hospital Guardamangia, Malta

R Pace Asciak, Department of Health Information, Guardamangia, Malta

\section{REFERENCES}

1 Dean G, Mc Loughlin H, Brady R, et al. Multiple sclerosis among immigrants in Greater London. BM 1976;i:861-4

2 Dean G, Brady R, McLoughlin H, et al. Motor neurone disease and multiple sclerosis among immigrants to Britain. Br J Prev Soc Med 1977:33:141-7.

3 Vassallo L, Elian M, Dean G. Multiple sclerosis in southern Europe. II: Prevalence in Malta in 1978. J Epidemiol Community Health 1979;33:111-3.

4 Department of Health Information Service. National Mortality registry. Guardamangia: The Department, 1978.

5 Dean G, Grimaldi G, Kelly R, et al. Multiple sclerosis in southern Europe. I. Prevalence in Sicily in 1975. J Epidemiol Community Health 1979;33:107-10.

6 Dean G, Savettieri G, Giordano D, et al. The prevalence of multiple sclerosis in Sicily. II. Agrigento city. J Epidemiol Community Health 1981;35:118-22.

7 Savettieri G, Daricello B, Giordano D, et al. The prevalence of multiple sclerosis in Sicily. I. Monreale city. J Epidemiol Community Health 1981:35:114-7.

8 Savettieri G, Elian M, Giordano D, et al. A further study on the prevalence of multiple sclerosis in Sicily: Caltanisetta city. Acta Neurol Scand 1986;73:71-5

9 Morganti G, Naccarato S, Elian M, et al. Multiple sclerosis in the Republic of San Marino. J Epidemiol Community Health 1984:38:23-8.

10 Poser CM, Donald W, Paty W, et al. New diagnostic criteria for multiple sclerosis: guidelines for research protocols. Ann Neurol 1983; 13:227-31

11 Elian M, Alonso A, Awad J, et al. HLA associations with multiple sclerosis in Sicily and Malta. Dis Markers 1987:5:89-99.

12 Central Office of Statistics. Demographic review of the Maltese Islands. Valletta: The Office, 1977

13 Central Office of Statistics. Demographic review of the Maltese Islands. Valetta: The Office, 1998

14 Compston A, Ebers G, Lassmann H, et al, eds. McAlpine's multiple sclerosis, third edn. London: Churchill Livingstone, 1998. 
15 Dean G. Elian M. Motor neurone disease and multiple sclerosis mortality in Australia, New Zealand and South Africa compared with England and Wales. J Neurol Neurosurg Psychiatry 1993;56:633-7.

16 Grimaldi LM, Salemi G, Grimaldi G, et al. High incidence and increasing prevalence of MS in Enna (Sicily), southern Italy. Neurology 2001:57:1891-3.

17 Savettieri G, Salemi G, Ragonese P, et al. Prevalence and incidence of multiple sclerosis in the city of Monreale, Italy. J Neurol 1998;245:40-3.

18 Rosati G, Aiello I, Pirastru MI, et al. A high-risk area for multiple sclerosis: a prevalence and incidence study in the District of Alghero. Ann Neurol 1987; 21:190-4.

19 Granieri E, Casetta I, Govani V, et al. The increasing incidence and prevalence of MS in a Sardinian province. Neurology 2000;55:842-7.

20 Granieri E, Tola R, Paolino E, et al. The frequency of multiple sclerosis in Italy: a descriptive study in Ferrara. Ann Neurol 1985;17:80-4.

21 Sironi L, Mamoli A, D'Alessandro G, et al. Frequency of multiple sclerosis in Valle d'Aosta, 1971-1985. Neuroepidemiology $1991 ; 10: 66-90$.

22 Granieri E, Casetta I, Tola MR. Epidemiology of multiple sclerosis in Italy and southern Europe. Acta Neurol Scand Suppl 1995;161:60-70.

23 Fernandez O, Luque G, San Roman C, et al. The prevalence of multiple sclerosis in the sanitary district of Velez, Malaga, southern Spain. Neurology 1994;44:425-9.
24 Bufill E, Blesa R, Galan I, et al. Prevalence of multiple sclerosis in the Region of Osona, Catalonia, northern Spain. J Neurol Neurosurg Psychiatry 1995;58:577-81

25 Uria DF, Calatayud MT, Abad P, et al. Multiple sclerosis in Gijon Health District, Asturias, northern Spain. Acta Neurol Scand 1997;96:375-9.

26 Dean G. Multiple sclerosis in Greece [letter]. Neuroepidemiology 1985;4:59-60.

27 Middleton LT, Dean G. Multiple sclerosis in Cyprus. J Neurol Sci 1991;103:29-36

28 Dean G, Aksoy H, Akalin T, et al. Multiple sclerosis in the Turkish- and Greek-speaking communities of Cyprus: a United Nations (UNHCR) bicommunal project. J Neurol Sci 1997; 145:163-8.

29 Dean G, Goodall J, Downie A. The prevalence of multiple sclerosis in the Outer Hebrides compared with north-east Scotland and the Orkney and Shetland Islands. J Epidemiol Community Health 1981;35:1 10-3.

30 Ben Hamida M. La sclerose en plaques en Tunisie: etude clinique de 100 observations. Rev Neurol (Paris) 1977;33:109-17.

31 Elian M, Dean G. Multiple sclerosis among the United Kingdom-born children of immigrants from the West Indies. J Neurol Neurosurg Psychiatry 1987:50:327-32.

32 Elian M, Nightingale S, Dean G. Multiple sclerosis among United Kingdom-born children of immigrants from the Indian subcontinent, Africa and the West-Indies. J Neurol Neurosurg Psychiatry 1990;53:906-1 1.

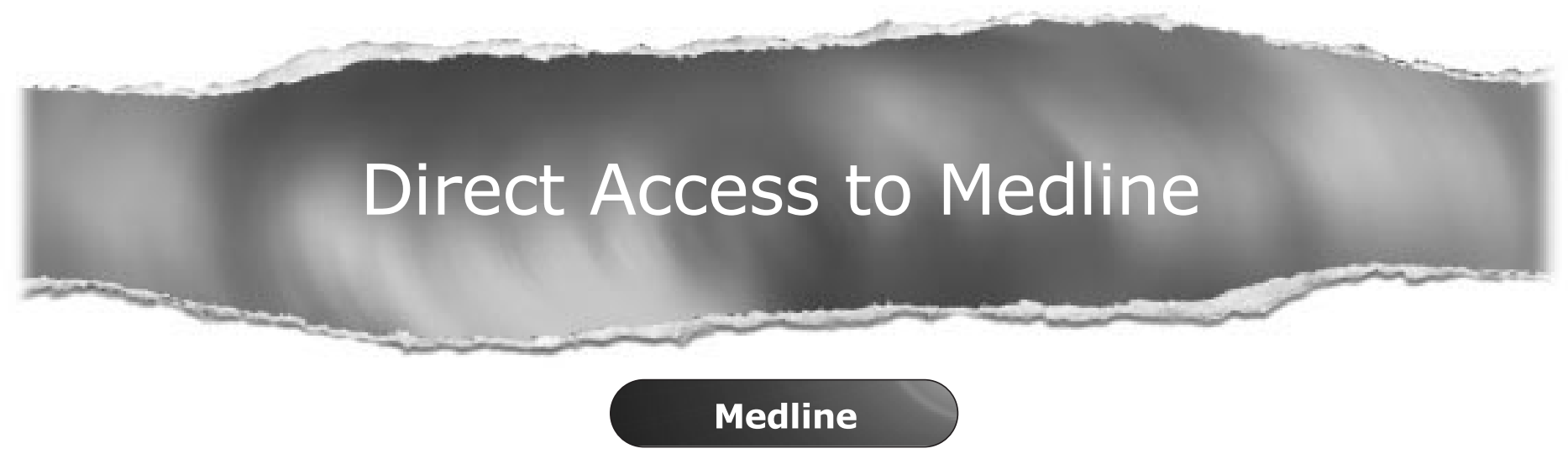

Link to Medline from the homepage and get straight into the National Library of Medicine's premier bibliographic database. Medline allows you to search across 9 million records of bibliographic citations and author abstracts from approximately 3,900 current biomedical journals.

\section{www.jnnp.com}

